\title{
ANTIGEN-SPECIFIC ELECTROPHORETIC CELL SEPARATION (ASECS): ISOLATION OF HUMAN T AND B LYMPHOCYTE SUBPOPULATIONS BY FREE-FLOW ELECTROPHORESIS AFTER REACTION WITH ANTIBODIES
}

\author{
ERNIL HANSEN and KURT HANNIG
}

Max-Planck-Institut für Biochemie, Am Klopferspitz, D-8033 Martinsried, F.R.G.

(Received 21 October 1981, accepted 2 December 1981)

The electrophoretic mobility of human lymphocytes can be reduced by incubation with surface antigen specific antibodies under non-capping conditions. This renders subpopulations of human peripheral blood lymphocytes accessible to separation by free-flow electrophoresis.

After reaction of lymphocyte preparations with anti-IgM antibody and a fluorescent second antibody, B lymphocytes showed a considerable shift in position in preparative cell electrophoresis and could be separated with high yield, purity and vitality. Similarly, a $\mathrm{T}$ cell subpopulation reactive with the monoclonal antibody $\mathrm{T} 811$ could be isolated, even though only small amounts of this antibody were bound, by using a double-sandwich method.

Non-specific antibody uptake via Fc-receptors did not contribute to the observed shift of antibody-labelled cells to lower electrophoretic mobility. Flow cytometric analysis showed that cells were separated according to their antigen density.

Thus cell electrophoresis can be used to separate antibody-labelled cells. With a flow rate of 100,000 cells/sec this method has a much higher separation capacity than fluorescence-activated cell sorting. The described method should be applicable to the separation of a wide range of cell populations for which specific antibodies are available.

Key words: human lymphocytes - free-flow electrophoresis - cell separation - monoclonal antibody - flow cytometry

\section{INTRODUCTION}

Free-flow electrophoresis has proven to be a powerful method for the separation of $\mathrm{T}$ and $\mathrm{B}$ cells, and of lymphocytes in various stages of differentiation and activation, for mouse and rat (Zeiller et al., 1971; Zeiller et al., 1976; for review see: Sherbet, 1978; Pretlow and Pretlow, 1979). Attempts to separate human lymphocytes, however, have been unsatisfactory (Stein et al., 1973; Häyry et al., 1975; Ault et al., 1976; Chollet et al., 1978).

Differences in the electrophoretic mobility of $\mathrm{T}$ and $\mathrm{B}$ cells from human 
peripheral blood have been described in a number of analytical investigations, but have been questioned by other authors (for review see Pretlow and Pretlow, 1979). Even if differences in surface charge density do exist, they seem to be too small to allow separation of human $\mathrm{T}$ and $\mathrm{B}$ lymphocytes by preparative cell electrophoresis.

The surface charge density of cells can be altered by reaction with antibodies. Changes in the electrophoretic mobility after incubation with appropriate antisera have been observed for erythrocytes, tumour cells and lymphocytes in various analytical systems (reviewed by Sherbet, 1978).

We describe here the use of conventional or monoclonal antisera for efficient preparative separation of human lymphocyte subpopulations by freeflow electrophoresis.

\section{MATERIALS AND METHODS}

\section{Cells}

$100-200 \mathrm{ml}$ of human peripheral blood from healthy donors were defibrinated by means of glass beads. Lymphocytes were prepared by Ficoll-Hypaque density centrifugation (MSL, $d=1.077 \mathrm{~kg} / \mathrm{l}$, Mediapharm, Aschaffenburg) as described by Böyum (1968) and washed 3 times in Puck-G (Difco, Detroit, MI). Approximately $1 \times 10^{6}$ lymphocytes were recovered per $1 \mathrm{ml}$ of blood. Contamination by monocytes was $7.3 \pm 2.3 \%$, as determined by non-specific esterase staining according to Yam et al. (1970).

\section{Antibody treatment}

For immunofluorescence and for electrophoretic separation B lymphocytes were stained with rabbit-anti-human-IgM antiserum (Behringwerke, Marburg), followed by incubation with FITC-labelled goat-anti-rabbit-Ig immunoglobulin (Behringwerke, Marburg). In another set of experiments monoclonal antibody $\mathrm{T} 811$, which reacts with a subpopulation of human $\mathrm{T}$ lymphocytes (Rieber et al., 1981), was used. Treatment with the monoclonal antibody was followed by incubation with TRITC-labelled rabbit-anti-mouseIg immunoglobulin and TRITC-labelled goat-anti-rabbit-Ig immunoglobulin (Nordic Immunology, Tilburg).

Before use all antisera were centrifuged at $15,000 \times \mathrm{g}$ for $30 \mathrm{~min}$ to remove protein aggregates. Antisera concentrations were adjusted to give an optimal uptake of antibodies by human lymphocytes without significant non-specific binding or cell aggregation. The anti-IgM antiserum was used in a $1 / 4$ dilution, and the monoclonal antibody in a $1 / 4$ dilution of the culture supernatant. The fluorescent second antibodies were adsorbed with $1 / 10$ volume of human mononuclear cells isolated from buffy coat preparations by Ficoll-Hypaque centrifugation, and used in a 1/4 dilution. 50-100 × 10 cells were stained when labelling was performed before cell electrophoresis, and $1 \times 10^{6}$ cells were stained in the fractions labelled after cell electrophore- 
sis. Twenty microlitres of the respective antiserum were used per $1 \times 10^{6}$ cells. Incubations were for $30 \mathrm{~min}$ at $4^{\circ} \mathrm{C}$ and were followed by 3 washes in Puck-G medium. Immunofluorescence was evaluated with a Zeiss fluorescence microscope under incident light. By keeping the cells strictly at $3-6^{\circ} \mathrm{C}$ throughout the experiments capping of antibodies on the cell surface could be avoided, and it was not necessary to add sodium azide to the media.

In control experiments the anti-IgM antiserum was replaced by a rabbitanti-Thy- 1 antiserum, and the monoclonal antibody $\mathrm{T} 811$ replaced by a nonrelevant monoclonal antibody.

\section{Cell electrophoresis}

Free-flow electrophoresis according to Hannig (1972) was performed on an Elphor VAP5 apparatus (Bender and Hobein, Munich). Electrophoresis buffers and conditions were those described earlier (Zeiller et al., 1975). The separation buffer consisted of $0.0187 \mathrm{~mol} / 1$ triethanolamine, $0.276 \mathrm{~mol} / \mathrm{l}$ glycine and $5 \mathrm{mmol} / 1$ potassium acetate, and was adjusted to $\mathrm{pH} 7.2$ with acetic acid. The conductivity was $8.4-9.0 \times 10^{-2} \mathrm{~S} / \mathrm{m}$, and the osmolarity was $0.30 \mathrm{osmol} / \mathrm{l}$. A 3 -fold more concentrated solution (without glycine) was used as electrode buffer. Untreated or antibody-treated cells were washed once in a mixture of electrophoresis buffer and Puck-G and once in electrophoresis buffer alone. Cells were adjusted to a concentration of $30-60 \times 10^{6}$ cells $/ \mathrm{ml}$ and subjected to electrophoresis at a flow rate of $5-6 \mathrm{ml} / \mathrm{h}$. The buffer flow rate was $550 \mathrm{ml} / \mathrm{h}$, resulting in an exposition time in the electric field for each cell of about $210 \mathrm{sec}$. Electrophoresis was performed at 200 $\mathrm{mA}$ and $800-1100 \mathrm{~V}$. The effective field strength (=measured field strength $\times 0.8$ ) was $60-86 \mathrm{~V} / \mathrm{cm}$. Fractions were collected in tubes containing $1 \mathrm{ml}$ of TC-medium Puck-G supplemented with 1\% BSA (Armour Pharmaceutical, Phoenix, AZ).

\section{Flow cytometry}

Cells were analysed for fluorescence intensity and narrow-angle $\left(2-10^{\circ}\right)$ light scatter intensity according to Herzenberg and Herzenberg (1978), using a flow cytometer developed in our laboratories, which is comparable to commercially available fluorescence activated cell sorters (FACS).

\section{RESULTS}

The aim of our studies was to investigate the distribution of antibodylabelled cells in free-flow electrophoresis, and to see to what extent antibody uptake would allow preparative isolation of the cells. Human blood lymphocytes were incubated with specific antibodies and then subjected to cell electrophoresis. Fluorescent second antibodies were used so that the position of antigen-positive cells could be traced easily by immunofluorescence microscopy. Each individual experiment was preceded by an electrophoresis of the untreated lymphocytes as a control. 
Separation of IgM-positive cells

The first set of experiments dealt with B cells, detected by a rabbit-antihuman-IgM antiserum and FITC-labelled goat-anti-rabbit-Ig immunoglobulin. Results from a representative experiment out of 12 can be seen in Fig. 1. Fig. $1 \mathrm{~A}$ shows the electrophoretic distribution of human blood lymphocytes and of IgM-positive cells. Only a slight difference in mean electrophoretic mobility (EPM) was observed between B cells and total lymphocytes. Some enrichment of B cells was seen in fractions of low EPM. These, however, comprised only a minute proportion of the IgM-positive cells.

A dramatic change in the distribution profile was observed, when cells were incubated with antibody prior to cell electrophoresis (Fig. 1B). A pronounced shoulder appeared in the region of low EPM. This shoulder was shown by immunofluorescence microscopy to contain the IgM-positive lymphocyte subpopulation. It was found to be shifted by about 5 fractions after antibody treatment, corresponding to a reduction of $15-20 \%$ in mean EPM.

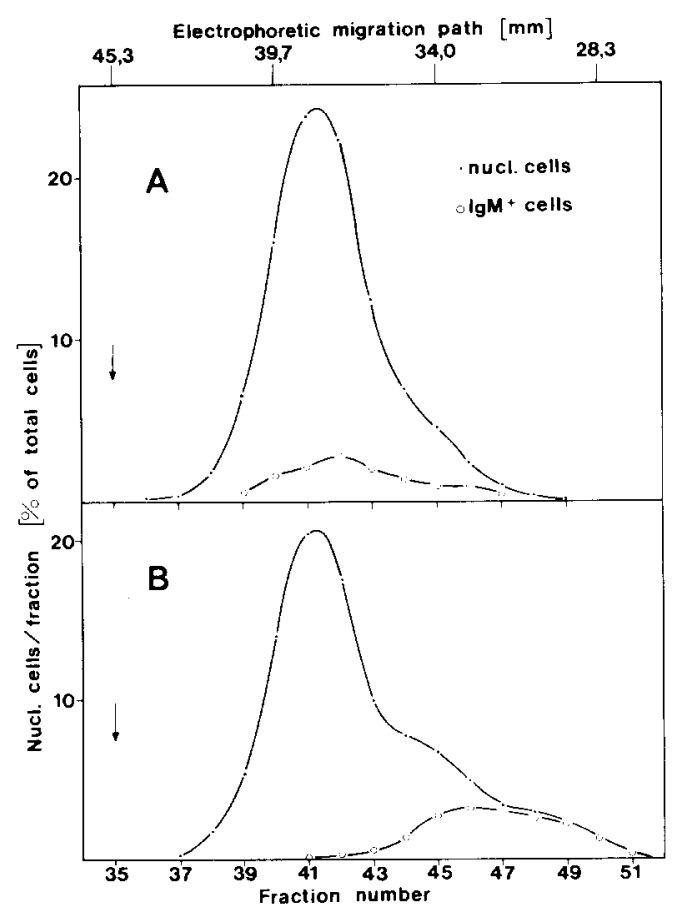

Fig. 1. Effect of anti-IgM antiserum on the electrophoretic mobility of human B cells. A: electrophoretic distribution of human blood lymphocytes. B cells were detected by staining with rabbit-anti-human-IgM and FITC-labelled goat-anti-rabbit-Ig antisera. B: electrophoretic distribution of antibody-treated cells. Lymphocytes were incubated with rabbitanti-human-IgM and FITC-labelled goat-anti-rabbit-Ig antisera (at $4^{\circ} \mathrm{C}$ ) before cell electrophoresis. Effective field strength: $71 \mathrm{~V} / \mathrm{cm}$. The arrow marks the position of formaldehyde-fixed human erythrocytes. 
TABLE 1

Enrichment of IgM-positive cells by free-flow electrophoresis. Data expressed as average \pm S.D. of 12 experiments.

\begin{tabular}{lccc}
\hline & \multicolumn{1}{c}{ Nucleated cells } & $\operatorname{IgM}^{+}$cells & \\
\cline { 2 - 3 } & Recovery (\%) & Purity (\%) & Recovery (\%) d \\
\hline $\begin{array}{l}\text { Lymphocyte preparation before } \\
\text { cell electrophoresis a }\end{array}$ & 100 & $15.2 \pm 2.1$ & 100 \\
$\begin{array}{c}\text { Sum of all fractions after electro- } \\
\text { phoresis of lymphocytes }\end{array}$ & $81.2 \pm 5.0$ & $14.8 \pm 1.7$ & 79 \\
$\begin{array}{c}\text { Sum of all fractions after electro- } \\
\text { phoresis of antibody-treated } \\
\text { lymphocytes b }\end{array}$ & $65.5 \pm 6.9$ & $19.2 \pm 3.8$ & 82 \\
$\begin{array}{c}\text { Fractions pooled after electro- } \\
\text { phoresis of antibody-treated } \\
\text { lymphocytes (pool L) c }\end{array}$ & $7.1 \pm 0.3$ & $89.2 \pm 3.7$ & 41 \\
\hline
\end{tabular}

a Lymphocytes were prepared from defibrinated human blood by Ficoll-Hypaque centrifugation. Monocyte contamination was $7.2 \pm 2.1 \%$.

b Lymphocytes were incubated with rabbit-anti-human-IgM and FITC-goat-anti-rabbit-Ig antisera before free-flow electrophoresis.

c Fractions were pooled in the region of low electrophoretic mobility so to contain half of the IgM-positive cells.

d Values were calculated from total cell recovery and percentage of IgM-positive cells. IgM-positive cells in the original lymphocyte preparation was set as $100 \%$.

Thus, B cells could be isolated in high yield and purity (Table 1). Fractions were present in the region of low EPM that consisted to more than $95 \%$ of IgM-positive cells. A pool which contained half of the antigen-positive cells (pool L in Table 1 ) was still about $89 \%$ pure. This pool L corresponds to fractions $47-51$ in the experiment shown in Fig. 1. Cell vitality, as measured by trypan-blue exclusion, was greater than $90 \%$ in all fractions except those of highest EPM, regardless of wether or not cells were treated with antibody before cell electrophoresis.

For untreated cells, mean cell loss occurred during transfer of cells to the electrophoresis buffer of low ionic strength. With antibody-treated cells, total cell recovery was reduced, mainly because of the additional centrifugation steps. Surprisingly, recovery of IgM-positive cells was unchanged at about $80 \%$, posssibly as a result of a higher resistance of antibody-coated cells to electrophoresis.

\section{Influence of antibody uptake on electrophoretic mobility}

B cells are heterogeneous in their quantitative expression of surface Ig. We therefore investigated the relationship of antigen density to the slowing effect of antibodies on the EPM. 

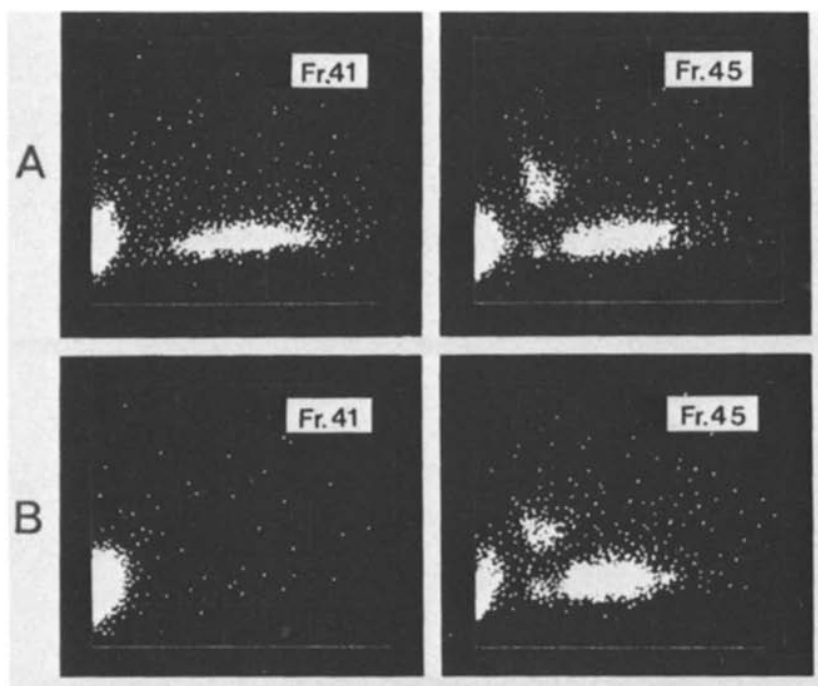

Fluorescence intensity $\longrightarrow$


Fig. 2. Flow cytometric analysis of electrophoretically separated human blood lymphocytes stained with rabbit-anti-human-IgM and FITC-labelled goat-anti-rabbit-Ig antisera. Fractions were taken from the electrophoretic separations shown in Fig. 1. A: fractions from the electrophoresis of untreated human lymphocytes. As a control for non-specific antibody uptake human lymphocytes were incubated with a rabbit-anti-rat-brain antiserum and FITC-labelled goat-anti-rabbit-Ig immunoglobulin. B: fractions from the electrophoresis of antibody-treated cells. Each dot represents the values for an individual cell of narrow-angle light scatter (y-axis), as a measure of cell size, and of fluorescence $(x$-axis), as a measure of surface antigen content.

Fractions of the experiment shown in Fig. 1, were analysed by flow cytometry. Fig. 2 shows the 2 -dimensional plots of narrow-angle light scatter signal, as a measure of cell size, and fluorescence signal, as a measure of antigen content, of individual cells.

When lymphocytes were stained for surface IgM after cell electrophoresis (A in Fig. 2), all fractions were found to contain a majority of small cells with only background fluorescence signals, and a small proportion of cells with bright fluorescence. The fluorescence intensities of these antigen-positive cells were widely distributed, but were clearly separate from antigennegative cells. A minor population of larger cells with low fluorescence intensities was observed in fractions of low EPM.

When electrophoresis was performed after antibody treatment (B in Fig. 2) fractions were obtained containing cells with background fluorescence only, or containing antigen-positive cells. The IgM-positive cells showed a distinct difference in fluorescence intensity between fractions of medium and of low EPM. The brightest fluorescence was seen on cells of lowest EPM. As antibody uptake of cells correlates with their antigen content this indicates that 
those B cells with the highest amount of surface IgM also experienced the most extensive reduction in their EPM. The cell volume of the IgM-positive lymphocytes was rather homogeneous. Thus electrophoresis separated the antibody-labelled cells according to their surface antigen density.

On average the observed fluorescence intensities were similar for cells stained before or after electrophoresis, indicating that no significant loss of antibodies from the cells occurred during the separation. The few larger cells with faint fluorescence were found in the same position (centred around fraction 45 in the experiment represented in Fig. 1) regardless of whether antibody incubation was performed before or after electrophoresis.

\section{Separation of a $T$ lymphocyte subpopulation reacting with monoclonal anti- body T811}

The described separation method should be applicable to any antibodydefined lymphocyte subpopulation. Because of their high significance and value for the classification of human lymphocytes, it was of interest to see, whether also monoclonal antibodies could be used in antigen-specific electrophoretic cell separation (ASECS).

The monoclonal antibody T811 (Rieber et al., 1981), which we chose as an example, reacts with a $\mathrm{T}$ cell subpopulation and consistently stained about $25 \%$ of the cells in our lymphocyte preparations. It was used in a concentration known from flow cytometric analysis to guarantee antibody saturation. However, the cells showed considerably lower intensity of staining in indirect immunofluorescence than with conventional antisera to lymphocyte surface antigens. No efficient separation by cell electrophoresis was achieved under these conditions.

We therefore applied a double-sandwich method, using TRITC-labelled rabbit-anti-mouse-Ig and goat-anti-rabbit-Ig immunoglobulins. TRITC-conjugates were chosen in preference to FITC-conjugates, because fluorescein significantly elevates the isoelectric point of immunoglobulin. When human erythrocytes and FITC-labelled, TRITC-labelled and unlabelled goat-antirabbit-Ig immunoglobulins were subjected to free-flow electrophoresis (effective field strength: $74 \mathrm{~V} / \mathrm{cm}$ ), the observed mean electrophoretic migration paths were $47.1 \mathrm{~mm}, 20.2 \mathrm{~mm}, 6.7 \mathrm{~mm}$ and $2.2 \mathrm{~mm}$, respectively. Thus the difference in charge density betweeh the lymphocyte cell surface and bound immunoglobulins can be better maintained by using rhodamine label.

The number of cells stained by the monoclonal antibody T811 was the same whether a single second antibody or the double-sandwich technique was used. Antigen-positive cells could be distinguished unambiguously from antigen-negative cells and from cells with faint fluorescence.

Fig. 3 shows the electrophoretic distribution of all nucleated cells and of the T811-defined $\mathrm{T}$ cell subpopulation before and after incubation with antibody. One representative experiment out of 7 is shown. The EPM of antigenpositive cells before incubation was similar to the mean EPM of all cells. After reaction with antibody the antigen-positive cells possessed a signifi- 


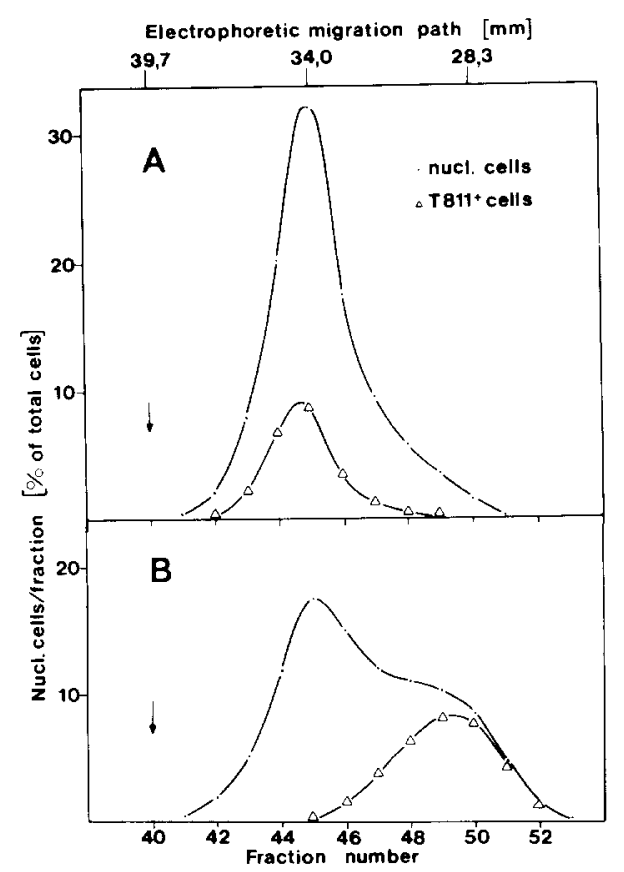

Fig. 3. Effect of monoclonal antibody T811 on the electrophoretic mobility of a human $T$ cell subpopulation. A: electrophoretic distribution of human blood lymphocytes. The $T$ cell subpopulation was detected by labelling with monoclonal antibody $T 811$ followed by TRITC-labelled rabbit-anti-mouse-Ig and TRITC-labelled goat-anti-rabbit-Ig immunoglobulins. B: electrophoretic distribution of antibody-treated cells. Lymphocytes were incubated with monoclonal antibody T811 and with TRITC-labelled rabbit-anti-mouseIg and goat-anti-rabbit-Ig immunoglobulins (at $4^{\circ} \mathrm{C}$ ) before cell electrophoresis. Effective field strength: $62 \mathrm{~V} / \mathrm{cm}$. The arrow marks the position of formaldehyde-fixed human erythrocytes.

cantly lower EPM, causing a bimodality in the electrophoretic profile. Cell recovery and purity greatly paralleled that obtained with the anti-IgM antiserum, as can be seen from Table 2. Again, recovery of antibody-labelled cells from electrophoresis was better than that of total cells, and cell viability was higher than $90 \%$ in all fractions, except those at the high EPM end of the distributions.

\section{Contribution of non-specific antibody uptake}

As a control for non-specific binding of antibodies via Fc-receptors and a test of its influence on the electrophoretic separation, lymphocytes were incubated with non-relevant conventional or monoclonal antibodies against Thy-1 antigen and with the respective fluorescent second antibodies. After this treatment 9 and $7 \%$ of cells respectively showed faint fluorescence. No effect on the electrophoretic profiles of total lymphocytes or of these 
TABLE 2

Enrichment of cells reactive with monoclonal antibody T811 by free-flow electrophoresis. Data expressed as average \pm S.D. of 7 experiments.

\begin{tabular}{llll}
\hline & \multicolumn{2}{l}{ Nucleated cells } & \multicolumn{2}{l}{ T811-reactive cells } \\
\cline { 2 - 4 } & Recovery (\%) & Purity (\%) & Recovery (\%) d \\
\hline $\begin{array}{l}\text { Lymphocyte preparation before } \\
\text { cell electrophoresis a }\end{array}$ & 100 & $23.2 \pm 3.2$ & 100 \\
$\begin{array}{c}\text { Sum of all fractions after electro- } \\
\text { phoresis of lymphocytes }\end{array}$ & $82.4 \pm 4.0$ & $23.2 \pm 2.8$ & 84 \\
$\begin{array}{c}\text { Sum of all fractions after electro- } \\
\text { phoresis of antibody-treated } \\
\quad \text { lymphocytes b }\end{array}$ & $67.1 \pm 7.2$ & $30.0 \pm 4.3$ & 87 \\
$\begin{array}{c}\text { Fractions pooled after electro- } \\
\text { phoresis of antibody-treated } \\
\text { lymphocytes (pool L) c }\end{array}$ & $11.2 \pm 0.6$ & $90.1 \pm 4.9$ & 43.5 \\
\hline
\end{tabular}

a Lymphocytes were prepared from defibrinated human blood by Ficoll-Hypaque centrifugation. Monocyte contamination was $7.5 \pm 2.7 \%$.

b Lymphocytes were incubated with monoclonal antibody T811 followed by TRITClabelled rabbit-anti-mouse-Ig and TRITC-labelled goat-anti-rabbit-Ig immunoglobulins before free-flow electrophoresis.

c Fractions were pooled in the region of low electrophoretic mobility so to contain half of the T811-positive chain.

d Values were calculated from total cell recovery and percentage of T811-positive cells. T811-positive cells in the original lymphocyte preparation was set as $100 \%$.

fluorescent cells was observed. Flow cytometry demonstrated that the cells with non-specific uptake of antibodies were mostly larger ('control' in Fig. 2), and that they were also present in the experiments with specific antisera (A and B in Fig. 2). These cells mainly consisted of monocytes, which were shown to have a 7\% lower mean EPM as compared to lymphocytes in several electrophoretic separations with or without specific antibody treatment.

Thus non-specific binding of antibodies via Fc-receptors can be disregarded in the electrophoretic separation of antibody-labelled cells.

\section{DISCUSSION}

Free-flow electrophoresis has been used very successfully in the separation of a wide variety of cells and cell organelles (reviewed by Hannig, 1972; Sherbet, 1978). Amongst the advantages of this method are its high separation capacity and that it is carrier-free, thus avoiding non-specific interactions of cells with solid surfaces. Cell electrophoresis has been especially useful in the separation of murine $T$ and B lymphocytes (Zeiller et al., 1971; for review see Sherbet, 1978; Pretlow and Pretlow, 1979). Unfortunately, it has 
not been found possible to use preparative cell electrophoresis to separate human lymphocytes (Stein, 1973; Häyry et al., 1975; Chollet et al., 1978), although a wide demand for preparative quantities of highly pure and vital human $\mathrm{T}$ and $\mathrm{B}$ cells exists in immunological and clinical research.

The method we describe here allows the efficient electrophoretic separation of human lymphocyte subpopulations on a preparative scale. It makes use of a decrease in the electrophoretic mobility (EPM) of cells after reaction with specific antibodies.

Analytical studies have already shown that antibodies can influence the EPM of cells (reviewed by Sherbet, 1978). A reduction in surface charge density has been observed in lymphocytes from various mammals after treatment with ALS or anti-Ig antisera (Bert et al., 1969; Phondke et al., 1970; Bert et al., 1971; Bona et al., 1972; Kaplan and Uzgiris, 1976). However, an increase in EPM (Von Boehmer, 1974; Zeiller et al., 1976), or a lack of any change (Bert, 1969; Wioland et al. 1976; Zeiller et al., 1976) has also been described. In all of these studies antibody-induced redistribution of surface antigens has to be considered since incubations at room temperature or $37^{\circ} \mathrm{C}$ were involved.

We have used antibody-induced changes in surface charge density for the first time in the preparative electrophoretic separation of cells. We observed a regular decrease in the EPM of human lymphocyte subpopulations by 15$20 \%$ after antibody treatment.

It is necessary to observe certain precautions in order to apply this technique of antigen-specific electrophoretic cell separation (ASECS). Some points may be important to be stressed. For any combination of cells and antibody it is necessary to determine optimal concentrations, resulting in maximal uptake of antibodies without cell aggregation or non-specific staining. Sandwich and double-sandwich methods can then be used to compensate for low antigen density. The low iso-electric point of immunoglobulin is retained best by using rhodamine instead of fluorescein as fluorescence label. Capping of antibodies on the cell surface should be avoided by use of low temperature or the addition of blocking agents. Under these conditions the observed decrease in EPM appears to be due to covering of surface charge by immunoglobulin.

The method described combines the high specificity of antibody-dependent separation techniques with the high separation power of free-flow electrophoresis. As with other methods involving antibodies, it should be kept in mind that the functional state of the cells may be changed in some way by reaction with antibody (Braun and Unanue, 1980). Generally, however, investigations of other cell surface antigens or receptors and most functional assays of lymphocytes are not impaired by antibody treatment. In the present case the antibodies can easily be removed from the cells by incubating at $37^{\circ} \mathrm{C}$ which results in capping and shedding of antigen-antibody complexes from the lymphocyte surface.

With methods such as immunoabsorbent chromatography, where antibodies 
bound to particles or solid surfaces are used problems can arise in the dissociation of antibody-bound cells from the matrix as well as from unspecific interactions with the carrier matrix. Smolka et al. (1979) have recently described a reduction in the EPM of human erythrocytes after reaction with relevant antibodies and with anti-Ig antibodies coupled to neutral plastic beads. They also observed an effect of the immunomicrospheres on unsensitized erythrocytes. In addition, they encountered difficulties in the removal of the bound particles. We consider that it is neither necessary nor desirable to add cell-particle interactions to the cell-antibody reaction for electrophoretic cell separation, especially when working with nucleated cells.

In the experiments described here the antiserum concentrations used to achieve optimal uptake of antibodies by the cells were about 10 -fold higher than those necessary for the detection of surface antigens by immunofluorescence microscopy. The consumption of antisera can be lowered by saving the supernatant after each incubation and recycling the antisera, since only a minimal proportion of antibody activity is removed during incubation.

However, antibody-dependent cell separation techniques are usually limited not by the amount of antibody, but by the separation capacity of the method. Thus cell recovery, cell vitality and the number of cells that can be processed in a reasonable time are the critical factors in immunoabsorbent chromatography and fluorescence activated cell sorting (FACS). In FACS, for example, the maximal flow rate is 5000 cells/sec (Herzenberg and Herzenberg, 1978), whereas free-flow electrophoresis allows separation of at least 100,000 cells/sec. Separation conditions can be held stable for many hours.

Cell recovery in free-flow electrophoresis ranges from 70 to $85 \%$ and cell viability in the relevant fractions is over $90 \%$. Dead cells are preferentially removed from the fractions of interest because they tend to acquire higher negative charge (Sherbet, 1978), whereas the antigen-positive cells are collected in the region of low EPM. In our experiments the vitality of the separated lymphocytes has not yet been verified in functional assays, but the use of electrophoretically separated cells in such tests is well documented (Zeiller et al., 1971; Zeiller et al., 1976; Sherbet, 1978), and antibody treatment is known not to interfere with most lymphocyte functions.

It is clear from the flow cytometric analysis that in our experiments cells were actually separated according to their antigen density. Therefore the method should also be applicable to the separation of cells in which only quantitative differences in surface antigens exist.

We also tested the possibility of applying monoclonal antibodies to ASECS. Despite of the low uptake of antibodies by the cells, monoclonal antibodies could be used to introduce the desired decrease in surface charge density using double-sandwich procedures.

Pretreatment of cells with antibodies greatly enhances the potential of free-flow electrophoresis. As a method for the isolation of large quantities of highly pure and viable human lymphocyte subpopulations, ASECS meets the requirements for wide application in immunological and clinical research. 
Moreover, the method may be of general use for the separation of any cell population or subcellular fraction or macromolecule that can be maintained in suspension and for which specific antibodies are available.

\section{ACKNOWLEDGEMENTS}

The authors thank Dr. E.P. Rieber, Institut für Immunologie der Universität München, for the generous gift of monoclonal antibody T811.

The excellent technical assistance of Mrs. Carola Eckelt and Mrs. Rita Wiemeyer is gratefully appreciated.

\section{REFERENCES}

Ault, K.A., A.L. Griffith, C.D. Platsoucas and N. Catsimpoolas, 1976, J. Immunol. 117, 1406.

Bert, G., A.L. Massaro, D. Lajolo di Cossano and M. Maja, 1969, Immunology 17, 1.

Bert, G., J.A. Forrester and A.J.S. Davies, 1971, Nature New Biol. 234, 86.

Bona, C., A. Anteunis, R. Robineaux and B. Halpern, 1972, Clin. Exp. Immunol. 12, 377.

Böyum, A., 1968, Scand. J. Clin. Lab. Invest. 21 (Suppl. 97 ), 31.

Braun, J. and E.R. Unanue, 1980, Immunol. Rev. 52, 3.

Chollet, P., P. Hervé, J. Chassagne, M. Masse, R. Plagne and A. Peters, 1978, Biomedicine, 28,119 .

Hannig, K., 1972, in: Techniques of Biochemical and Biophysical Morphology, Vol. 1, eds. D. Glick and R.M. Rosenbaum (Wiley, New York) p. 191.

Häyry, P., L.C., Andersson, C. Gahmberg, P. Roberts, A. Ranki and S.. Nordling, 1975, Isr. J. Med. Sci. 12, 1299.

Herzenberg, L.A. and L.A. Herzenberg, 1978, in: Handbook of Experimental Immunology, ed. D.M. Weir (Blackwell, Oxford) Ch. 22.

Kaplan, J.H. and E.E. Uzgiris, 1976, J. Immunol. 117, 1732.

Phondke, G.P., K. Sundaram and P. Sunaresan, 1970, Nature 225, 79.

Pretlow, T.G. and T.P. Pretlow, 1979, Int. Rev. Cytol. 61, 85.

Rieber, E.P., J. Lohmeyer, D.J. Schendel and G. Riethmüller, 1981, Hybridoma in press.

Sherbet, G.V., 1978, The Biophysical Characterization of the Cell Surface (Academic Press, New York) p. 36.

Smolka, A.J.K., S. Margel, B.H. Nerren and A. Rembaum, 1979, Biochim. Biophys. Acta $588,246$.

Stein, G., H.D. Flad, R. Pabst and F. Trepel, 1973, Biomedicine 19, 388.

Von Boehmer, H., 1974, in: Progress in Immunology II, Vol. 1, eds. L. Brent and J. Holborow (North-Holland, Amsterdam) p. 312.

Wioland, M., M. Donner and C. Neauport-Sautes, 1976, Eur. J. Immunol. 6, 273.

Yam, L.T., C.Y. Li and A. Crosby, 1970, Am. J. Clin. Pathol. 55, 283.

Zeiller, K., K. Hannig and G. Pascher, 1971, Hoppe-Seylers Z. Physiol. Chem. 352, 1168.

Zeiler, K., R. Löser, G. Pascher and K. Hannig, 1975, Hoppe-Seylers Z. Physiol. Chem. $356,1225$.

Zeiller, K., G. Pascher and K. Hannig, 1976, Immunology 31, 863. 